\title{
Domestic funding for health policy and systems research: why is it invisible?
}

\author{
Geetanjali Lamba, ${ }^{a, b}$, Livia Dal Zennaro ${ }^{a}$, Solip Ha $\mathrm{Ha}^{\mathrm{a}}$ and \\ Sonam Yangchena \\ a Alliance for Health Policy and Systems Research, World Health Organization, Geneva, Switzerland \\ b Corresponding author: lambag@who.int
}

\section{Article history}

Publication date: 10 November 2021 Citation: Lamba G, Dal Zennaro L, $\mathrm{Ha}$ S, Yangchen S. Domestic funding for health policy and systems research: why is it invisible? Public Health Res Pract. 2021;31(4):e3142117. https://doi. org/10.17061/3142117

\section{Key points}

- Domestic funding for health policy and systems research (HPSR) is important because it can help ensure that research aligns with local priorities in low- and middle-income countries (LMICs)

- As national financial resources increase and international donor assistance decreases, HPSR will rely more on domestic funding

- Despite many efforts, it is impossible to reliably estimate HPSR funding in most LMICs

- Recommendations to address these issues include creating mechanisms to ensure funds are allocated to HPSR, creating a database to track HPSR funding and advocating for the value-add of HPSR

\section{Abstract}

Objectives and importance of study: Health policy and systems research (HPSR) informs stronger health systems but it remains chronically underfunded, especially in low- and middle-income countries (LMICs). Domestic funding for HPSR helps to ensure research is aligned with local priorities. As LMICs transition from international donor assistance for health research, HPSR will increasingly need to rely on domestic funding. However, domestic funding flows remain poorly understood. This study aims to understand how, and how much, HPSR is funded domestically in LMICs. It explores challenges associated with estimating HPSR funding and suggests strategies to improve domestic support for HPSR.

Study type: Mixed methods.

Methods: We reviewed regional technical reports commissioned by the Alliance for Health Policy and Systems Research, which studied domestic HPSR funding through desk reviews and key informant interviews. Data were qualitatively and quantitatively analysed and findings were triangulated. We also conducted a separate bibliometric analysis to understand HPSR capacity.

Results: Despite many efforts from different angles, we were unable to reliably estimate HPSR funding in most of the countries studied. The reasons for this included a lack of a common understanding of HPSR, difficulty disentangling HPSR funding from other research funding, and bureaucratic and data transparency hurdles. We also describe which domestic bodies fund HPSR and examine the interrelatedness of HPSR capacity and funding.

Conclusion: Domestic funding flows for HPSR remain almost invisible. This finding informs concrete recommendations to improve HPSR funding transparency, and for national research funders and ministries of health and finance to invest in HPSR for stronger health systems. 


\section{Introduction}

Health policy and systems research (HPSR) is an interdisciplinary field that seeks to understand and improve the relationship between health policy and health systems, and broader health determinants, to improve health. ${ }^{1}$ HPSR is essential for strong and equitable health systems ${ }^{2}$ and is cost-effective because it improves the use of existing financial and human resources. ${ }^{3}$ Stronger health systems are important for acheiving national and global health goals. ${ }^{4}$

Although HPSR funding has increased over time, with donor support to low- and middle-income countries (LMICs) increasing from US\$75 million in 2000 to about US $\$ 540$ million in $2010^{5}$, HPSR remains chronically underfunded compared with other types of health research. 6,7 Between 2000 and 2014, only approximately $2 \%$ of all donor aid for health and population projects was spent on HPSR, with top donors including the United States, the Global Fund, the World Bank and the Bill and Melinda Gates Foundation. 5,8 Previous literature shows that $53-69 \%$ of HPSR in LMICs is funded by international donor assistance. ${ }^{8,9}$ For middle-income countries, the proportion of HPSR funding from international donor assistance is less and the proportion of national government funding is more, when compared to lowincome countries. ${ }^{5}$

National funding for HPSR is important for three reasons. Firstly, domestic funding for HPSR projects can increase the likelihood that the research is responsive to local needs and favours local capacity strengthening. ${ }^{8}$ National HPSR funding is therefore a potential indicator of local HPSR knowledge and capacity. Secondly, as national financial resources increase and countries become less reliant on international donor assistance for HPSR, they will transition to national funding. Developing supportive infrastructure for HPSR financing could contribute to smooth transitions. ${ }^{10}$ Thirdly, national investment in HPSR can inform more efficient resource allocation and governance mechanisms, helping national governments to make cost-effective health system decisions. For all these reasons, strong domestic organisational systems and structures for HPSR are essential.

Previous work about HPSR funding focuses on tracking resource flows via different methodologies. 5,8,9 For instance, Grepin et al. analysed data from the Organisation for Economic Co-operation and Development's (OECD's) Creditor Reporting System database to estimate annual funding available for HPSRrelated activities, developing a list of 204 keywords and a subsequent search algorithm. ${ }^{5}$ This extensive keyword analysis highlighted HPSR definitional challenges and a lack of common understanding among donors. (The authors tracked overseas donor aid, so this does not reflect funding for HPSR at the level of national governments).
Bennett et al. surveyed both HPSR research institutions and international donors for HPSR and found that $27 \%$ of all HPSR grants in LMICs came from national governments, although the data does not show further granularity. ${ }^{8}$ Rather than source data from national governments, Gonzalez Block et al. surveyed 176 HPSR producer institutions across 39 LMICs to determine the scale of HPSR funding, finding that international sources and national governments accounted for $69 \%$ and $26 \%$ of funding respectively. ${ }^{9}$ It is important to note that these two studies were published in 2003 and 2008 so their results are dated and HPSR has grown tremendously since then. ${ }^{11}$

These studies have concentrated on characterising international donor funding, but there has not previously been an attempt to characterise domestic funding for HPSR in detail. Overall, domestic funding flows for HPSR, and the challenges associated with tracking them, therefore remain poorly understood. Understanding the reasons behind HPSR funding challenges may inform strategies to address them.

\section{The role of the Alliance}

Seeking to understand domestic funding further, the World Health Organization (WHO) Alliance for Health Policy and Systems Research (the Alliance) commissioned a research program in 2020 , which aims to discover how and how much HPSR is funded by national governments as opposed to global funders, and the challenges associated with this. Projects were conducted in each of the six WHO regions, and they are reported on in this current issue of Public Health Research \& Practice. $^{12}$

This paper aims to understand how much and how HPSR is funded domestically. It also aims to present key challenges associated with estimating HPSR funding so that concrete recommendations for stronger global HPSR funding mechanisms can be developed.

\section{Methods}

Six projects were conducted by regional teams in each of six WHO regions in August and September 2020. Data were collected for 67 countries via desk reviews and in-depth interviews with key stakeholders. Reports developed by the regional teams and the overarching global report are the chief sources of data for this paper. ${ }^{13-18}$

The regional teams searched databases; reviewed annual reports and budget reports from health agencies, national accounts and national science funding agencies; and reviewed documents describing national research funding systems and priorities. Search terms and strategies were harmonised across teams but were also adapted to reflect regional differences. Teams also purposively sampled funders, policy makers and researchers in 47 LMICs, and conducted more than 
140 semi-structured interviews. High-income countries were excluded from analysis.

Quantitative data were extracted from regional reports into Microsoft Excel (Redmond, Washington: Microsoft Corporation; 2021) and analysed descriptively. Themes for inclusion were identified inductively from qualitative data, then qualitative data from the regional reports were extracted and thematically analysed.

A bibliometric analysis was also performed to identify trends in HPSR publications across 47 LMICs, with PubMed and Embase as primary sources, using the following terms: medicine AND health policy AND health systems research AND health policies AND systems research AND funding, combined with name of 'country'. These search terms were in line with the search terms used by the regional teams. Peer-reviewed articles published between 1 January 2010 and 31 December 2020 were included, irrespective of language. Findings were triangulated to compare, validate and expand on key thematic areas.

\section{Methodological limitations}

Quantitative data about HPSR financing were extracted from analysis of regional reports. Although each regional study developed common research protocols, specific quantitative indicators of HPSR financing varied across regions, leading to difficulty in direct comparison. Additionally, data for HPSR-specific funding was not available for most countries. Data collection occurred during the global coronavirus disease 2019 (COVID-19) pandemic, limiting access to key informants. Table 1 summarises country data availability.

Table 1. Country-level HPSR data availability

\begin{tabular}{lc}
\hline Aspect of country-level data availability & $\begin{array}{c}\text { Number of countries } \\
n(\%)\end{array}$ \\
\hline All countries in study population & 47 \\
Semi-structured interviews & $42(89)$ \\
Bibliometric analysis & $47(100)$ \\
Quantitative data for domestic funding & $8(17)$ \\
for HPSR & \\
Multiple years of quantitative data for & $4(8.5)$ \\
domestic HPSR funding & \\
Data about governance systems for & $23(49)$ \\
HPSR & \\
\hline
\end{tabular}

HPSR = health policy and systems research

\section{Ethics}

No additional human subjects were recruited for this study. For this reason, no additional ethics approvals were sought. Consent was obtained for interviews for individual regional reports, as per local requirements.

\section{Results}

Table 2 summarises emergent themes, the number of countries with data for each theme and provides illustrative quotes from regional reports. See Supplementary Table 1 (available from: doi.org/10.6084/ m9.figshare.16782928.v1) for more detail on the specific countries in which each theme occurs.

\section{Domestic funding flows to HPSR}

The total study population was 47 countries but, as described in Table 1, quantitative data was only available for eight countries. This section summarises the best available data from 2018 to 2020 for these eight countries. Indicators for estimating HPSR expenditure varied between countries and included estimates of: absolute dollar value; percentage of ministry of health $(\mathrm{MoH})$ budgets; percentage of health research budgets; and proportion of grant value allocated to health research.

In India, the National Health Mission allocated approximately US\$10 million or $0.25 \%$ of its budget in 2019 to HPSR for reviews, research and surveys. ${ }^{17}$ In Thailand, $4.3 \%$ of health research expenditure was allocated in 2020 to HPSR. ${ }^{17}$ In Nepal, an estimated $40 \%$ of the Nepal Health Research Council's annual budget was allocated in both 2019 and 2020 to HPSR. ${ }^{17}$ In Malaysia, experts interviewed estimated that $5 \%$ of the health research budget was allocated in 2020 to HPSR. ${ }^{16}$ In 2019, 2\% of the Philippine Health Insurance Corporation's annual operating costs were allocated to research, mostly to HPSR. The Philippines Department of Health (DOH) also has a program entirely dedicated to HPSR. ${ }^{16}$

Examining research grants as an indicator of HPSR funding, in Argentina, between 2010 and 2018, 55\% of health research grants disbursed by the Ministry of Health went to HPSR research projects. This amounted to approximately $\$$ US7.5 million in 9 years. ${ }^{14}$ In Brazil, from 2010 to 2019, approximately US\$16.7 million was allocated to HPSR projects by their national health research program, approximately $10 \%$ of total project allocations. ${ }^{14}$ In Mexico, from 2012 to 2018, US\$3.9 million in HPSR-funded projects were identified, approximately $9 \%$ of total health research project numbers. ${ }^{14}$

The implication of this lack of quantitative data is that quantifying domestic funding for HPSR is difficult for most countries. The differences in indicators used make meaningful comparisons between countries challenging.

\section{Challenges associated with tracking HPSR funding flows}

Countries vary in how they define and capture research under the broad HPSR umbrella. Becerra-Posada et al. noted "there is not a clear definition of HPSR among national and subnational institutions that fund research."14 Associated definitions include 'health services research', 
Table 2. Summary of emergent themes

\begin{tabular}{|c|c|c|}
\hline Theme & $\begin{array}{l}\text { Number of countries that } \\
\text { raised each theme } n(\%) \\
\qquad(N=47)\end{array}$ & Illustrative quotes from regional reports \\
\hline \multicolumn{3}{|l|}{ Quantitative data for HPSR } \\
\hline $\begin{array}{l}\text { Quantitative data for } \\
\text { domestic funding } \\
\text { available }\end{array}$ & $8(17)$ & NA \\
\hline $\begin{array}{l}\text { - HPSR-specific data } \\
\text { unavailable, proxy } \\
\text { indicator used }\end{array}$ & $32(68)$ & $\begin{array}{l}\text { "We looked at the overall research and development funding envelope by } \\
\text { countries. Within this envelope, we narrowed down on spending levels on } \\
\text { medical, health and social science research fields, through which HPSR } \\
\text { most likely is funded." } 13\end{array}$ \\
\hline $\begin{array}{l}\text { - No quantitative data } \\
\text { available }\end{array}$ & $10(21)$ & $\begin{array}{l}\text { "No [country] had explicit national funding or budget line items for HPSR } \\
\text { (at both national and institutional levels) in any of the published national } \\
\text { reports audited as part of this review... Informal discussions with focal } \\
\text { persons in [nine countries] further confirmed the lack of existence of } \\
\text { explicit national funding or budget item line for HPSR."15 }\end{array}$ \\
\hline $\begin{array}{l}\text { Tracking funding for HPSR } \\
\text { is challenging }\end{array}$ & $18(38)$ & $\begin{array}{l}\text { "Limitations arise from the international classification of research } \\
\text { spending which ... does not prescribe a statistical code to this field, } \\
\text { making it impossible to separate HPSR funding levels from other } \\
\text { research, mak[ing] HPSR expenditure completely invisible through a } \\
\text { science funding statistical system."13 }\end{array}$ \\
\hline $\begin{array}{l}\text { Governance and systems for } \\
\text { HPSR funding a }\end{array}$ & $23(49)$ & $\begin{array}{l}\text { "The governance system and role of the government is very important to } \\
\text { discuss health systems and policies ... research should be prioritised and } \\
\text { strong advocacy is also needed to raise political leaders' interest."18 }\end{array}$ \\
\hline $\begin{array}{l}\text { HPSR funding and HPSR } \\
\text { capacity are linked }\end{array}$ & $47(100)$ & $\begin{array}{l}\text { "In Tunisia, the focus of the health research plan is not to direct the type } \\
\text { of research conducted, but instead, to develop health research capacity } \\
\text { and research systems." } 15\end{array}$ \\
\hline $\begin{array}{l}\text { HPSR funding less } \\
\text { prioritised or understood } \\
\text { than other health research }\end{array}$ & Almost all & $\begin{array}{l}\text { "Not much priority has been given to HPSR... One of the barriers that the } \\
\text { country faces is the lack of awareness and interest... Secondly, major } \\
\text { funds are available for clinical research so a large proportion goes into } \\
\text { the above-mentioned area."13 }\end{array}$ \\
\hline
\end{tabular}

NA = not applicable

a See Supplementary Table 2 for more detailed information (available from: doi.org/10.6084/m9.figshare.16611658.v3)

b An exact number could not be confirmed

'healthcare management research', 'implementation research', 'operational research', 'health economy research', 'health policy research', 'health workforce research' and 'healthcare leadership and governance research', among others. Because of the absence of universal deinitions, quantifying HPSR funding is challenging, as is cross-country comparison.

HPSR research is interdisciplinary and often difficult to disentangle from broader health or public health research projects that include components of HPSR. It is sometimes funded under economic, social science or other research categories, leading to difficulty with tracking funding flows. Furthermore, HPSR funding does not generally originate from one national organisation, rather from many actors and institutions. In Peru, BecerraPosada et al. find "financing for HPSR is through a series of funding channels, first through institutional funds linked to internal budget, and joint INS [National Institute of
Health]/external funds, in interdependence with other institutions... and other funds that might come from international sources and foundations." 14

Further complexity is added when international funding must be channelled through domestic mechanisms, such as in Nepal, or in cases of domestic funding for extramural research, such as in India. ${ }^{17}$ It is difficult to ascertain whether such funding is domestic or international. Lastly, HPSR does not often have its own budget line in these domestic institutions. Indeed, Gotsadze states that HPSR-specific expenditure can be "completely invisible". ${ }^{13}$

Regional teams also noted that in many countries structural, bureaucratic, data transparency and public accounting hurdles add to difficulty in quantifying domestic funding for HPSR. 


\section{Trends in HPSR funding}

Funding varies between years (see Figure 1). In Brazil, funding for HPSR was more than US\$10 million in 2013 but dropped to approximately US\$200 000 in $2014 . .^{14}$ There is no clear reason from either the interviews or desk reviews for this large variation. In Argentina, although the overall budget of the Ministry of Health increased between 2010 and 2018, the amount spent on HPSR remained relatively constant and trended slightly downward, indicating a decreasing proportion spent on HPSR over time..$^{14}$ In Mexico, the Sectoral Fund for Research in Health and Social Security (FOSISS), the domestic agency responsible for most HPSR funding, issued its final call for proposals in 2018, with no subsequent HPSR funding allocated from this channel. ${ }^{14}$

\section{Governance system for HPSR}

Supplementary table 2 (available from: doi.org/10.6084/ m9.figshare.16611658.v3) provides an overview of funders, research institutions and decision makers for health research and HPSR. Twenty-three of the 47 countries are included, with data from other countries unavailable.

Nine LMICs include international and bilateral donor agencies in their HPSR decision-making process; interviewees said these agencies support national stakeholders with funding and technical support for priority setting and developing policies for health research.

Supplementary Table 2 shows it is possible for national health research plans to prioritise HPSR. For example,
Liberia specifically includes HPSR in its national health plan and Jamaica includes HPSR in its national health agenda. ${ }^{14,18}$ Regional reports from these countries noted the benefit of multistakeholder collaboration and advocacy in the relatively early phases of priority setting. Advocacy is led and formalised in Jamaica by the Essential National Health Research Committee, which is the governing and funding body for coordination of health research. ${ }^{14}$

HPSR-specific institutes exist in several countries. Thailand's well-established Health Systems Research Institute (HSRI) has resulted in strong context-specific HPSR and a comprehensive understanding of its importance. ${ }^{17}$

Innovative financing mechanisms for HPSR are feasible. For example, in Jamaica the CHASE fund, which receives revenue from gambling and the national lottery board, has a dedicated budget for HPSR and tobacco taxation revenue also finances health research.

\section{Capacity and funding for HPSR are linked}

When countries allocate domestic funds for HPSR, some are directed to capacity building. Capacity building is a funding focus for some countries, for example, in Tunisia ${ }^{15}$, HPSR publications were one indicator for domestic HPSR capacity used by multiple regional reports. Because HPSR funding is difficult to measure, HPSR capacity measured through publications can be a pragmatic proxy for HPSR funding. To understand HPSR funding through the generation of HPSR publications, we conducted a bibliometric analysis.

Figure 1. Trends in HPSR funding in Brazil, Mexico and Argentina, 2010-2019

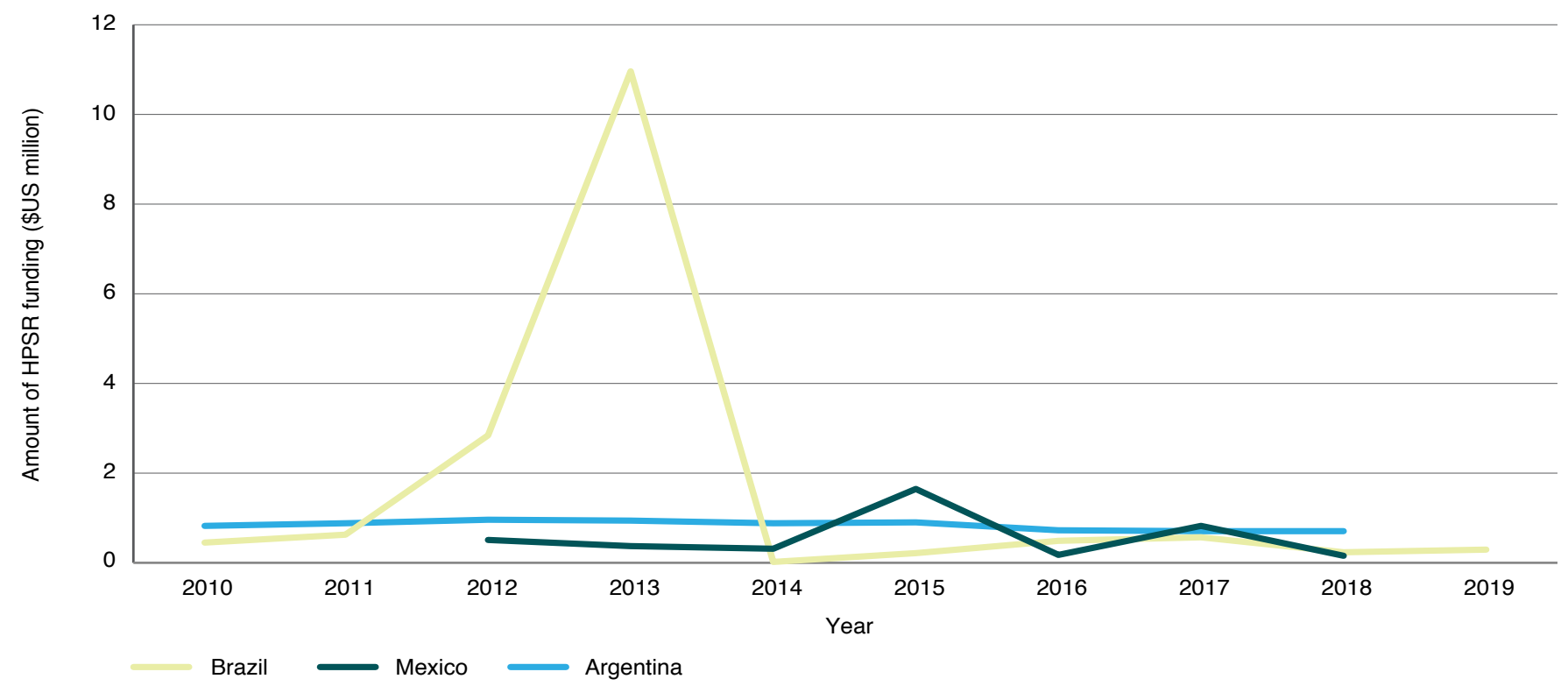

Source: Becerra-Posada F, dos Santos Boeira L, García-Godoy MB, Lloyd E, Martínez-Sánchez HX, O'Donnell C, et al. Politics and political determinants of health policy and systems research funding in selected countries in Latin America and the Caribbean. ${ }^{14}$ 
Supplementary Table 3 (available from: doi. org/10.6084/m9.figshare.16614190.v1) presents the volume of published HPSR papers per country between 2010 and 2020 as ascertained from the bibliometric analysis. Research capacity varies highly between countries but we found a positive correlation between HPSR capacity and funding. For example, India has both high publication and funding levels for HPSR. Its high publication volume is perhaps also a result of field-building efforts, which themselves also depend on funding. Conversely, when funds are not allocated to HPSR, for example in Libya, Somalia and Djibouti, there is significantly less capacity, as reflected by El Rabat and Mekky in the bibliometric indicators for the Eastern Mediterranean region. ${ }^{15}$

Figure 2 shows an increase in HPSR publications over time. Despite this visible increase, corresponding increased funding is not visible because there are no monitoring systems for funding flows. However, we can speculate that HPSR funding must be increasing because financial resources are required to support HPSR publications.

Additionally, countries with the highest number of publications (China, India and Brazil, see Supplementary Table 3, available from doi. org/10.6084/m9.figshare.16614190.v1), also have a high number of HPSR specialised institutions (see Supplementary Table 2, available from doi.org/10.6084/ m9.figshare.16611658.v3). Comparatively, countries with the least number of publications (Cote d'Ivoire, Sierra Leone and Liberia) do not have any HPSR-specific research institutions outside their ministries of health.

Country income level correlate to both HPSR capacity and funding source. Upper-middle income countries had more publications and a higher percentage of funding from academia (68.3\% of funding) compared with lowincome countries, which had fewer publications and funding predominantly from international grants $(79.5 \%$ of funding). ${ }^{15}$

\section{Biomedical and clinical research receives more funding than HPSR}

Countries often give more funding to biomedical and clinical research than to HPSR, and this can be politically motivated. ${ }^{17}$ Globally, clinical and biomedical research receives a larger proportion of health research funding than HPSR. In Malaysia, interviewees estimated the breakdown for biomedical/clinical research, public health research and HPSR as approximately $80 \%, 15 \%$, and $5 \%$ respectively. In Ghana, an interviewee emphatically stated "biomedical research receives the most funding, NOT HPSR."18

Funding decisions for research are also based on national political health priorities. In Nepal, an interviewee stated that "political commitment plays a crucial role in funding allocations". ${ }^{17}$ Reddy et al. found in Sri Lanka, Republic of Maldives, Nepal and Thailand that when governments prioritised achieving Sustainable Development Goals or Universal Health Coverage, projects associated with these were often funded. ${ }^{17}$

Multilateral organisations can also help with efforts to fund HPSR research: one interviewee from Nepal stated that "if WHO endorses certain research evidence and recommends for policy adoption, it is easier to endorse such evidence in the policy." ${ }^{\prime 17}$

Becerra-Posada et al. noted that although respondents from all countries recognised the value of HPSR, researchers were nevertheless more engaged in 'pushing' research results rather than policymakers 'pulling' them. ${ }^{14}$

\section{Discussion and recommendations}

HPSR is a public good with arguably little commercial value or profitability, and thus primarily relies on philanthropic and government sources of funds. Domestic sources of funds may correlate to research that aligns

Figure 2. Total HPSR publications per year, 2010-2020 in 47 countries studied $^{a}$

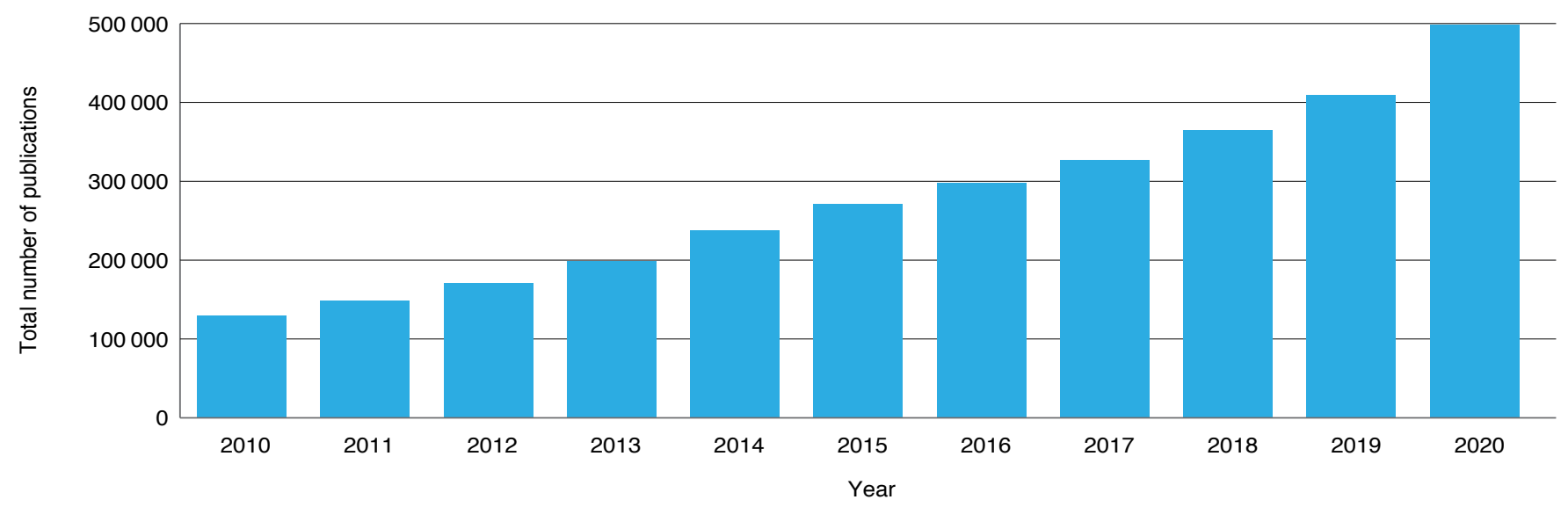

a See Supplementary Table 3 for total volume of published papers per country, 2010-2020, as ascertained by bibliographic analysis. Available from: doi.org/10.6084/m9.figshare.16614190.v1 
with and informs local priorities. However, our primary finding is that there a dearth of internationally comparable data describing national-level HPSR funding flows. This supports existing studies and confirms that systems to track HPSR funding are still lacking. $., 8,9$

Tracking HPSR funding flows is essential for many reasons. It allows governments to evaluate, improve and learn from their HPSR programs, enables cross-country comparison and informs advocacy efforts. ${ }^{5}$ Although HPSR publications are tracked through databases, there is no corresponding system for tracking HPSR funding. A global HPSR funding database could inform both evaluation and advocacy efforts. Devex, a database for global development funding, provides a precedent. ${ }^{19}$

We find that identifying HPSR funding data is complex because of a lack of pragmatic common understanding of what HPSR entails. Many definitions of HPSR exist, including that used by the Alliance for HPSR. ${ }^{1}$ There are also similarities between HPSR, implementation research, operational research and other research categories. Although definitional debates and nuances between these categories exist in academia, definitional clarity has little practical relevance to the actors who make HPSR funding decisions, including those who work in ministries of finance or health. From the viewpoints of these stakeholders, overall funds allocated to HPSR are small, definitions overlap but all aim to improve health systems operations and performance. Thus, definitional clarity is useful for those who conduct HPSR, but less important for those who use or fund HPSR.

Relatedly, HPSR-specific resources are difficult to segregate from funding for other health research because components of HPSR are often enmeshed in other programs. Structural, bureaucratic, data transparency and public accounting hurdles also exist. The creation of separate budget lines for HPSR funding in public accounts may simplify tracking, as it did with the creation of and allocation of funds to an HPSR line item in the Philippines in 2013. ${ }^{5}$

While in institutions with too many existing budget lines this may be unpopular, there should nevertheless be specific mechanisms to allocate funding to HPSR. One strategy is to 'ring-fence' funding by developing binding agreements dedicating percentages of health research funding to HPSR. This can be done at many levels, for example as required HPSR allocations in overall health budgets, health research budgets, or hospital budgets. Some countries, for example Malaysia, have standalone institutes for HPSR, essentially ring-fencing funds. ${ }^{16}$ Another mechanism is earmarking certain percentages of health tax revenue, as in the Philippines. ${ }^{20}$ Steady sources of funding for HPSR may require innovative thinking. ${ }^{21}$

Our analysis confirms previous findings that HPSR funding is inadequate and that health research funding generally prioritises biomedical and clinical research.5,8,9 Consequently, anecdotal reports suggest that HPSR researchers often write funding proposals using biomedical jargon so as to align with funders' language.
In most countries, we find that HPSR is not explicitly on the national research agenda and that the added value of HPSR among decision makers is underappreciated. Gonzalez Block and Mills agree, noting that even funds earmarked for HPSR, received by governments from multilateral organisations, may not be spent because decision makers are not prioritising HPSR. ${ }^{9}$ They estimate that approximately three times as much funding is earmarked for HPSR from governments than is actually spent at the institutional level. ${ }^{7}$ Education, awarenessraising and advocacy efforts are important in helping policy makers recognise HPSR's promise. ${ }^{11}$ Thought should be given to effective communication towards this goal.

Formulating HPSR that resonates with specific funders is one way to improve recognition of its added value and to elicit increased funding; HPSR that aligns with national political priorities is often funded. Koon et al. suggest framing research to emphasise value considerations. ${ }^{22}$ HPSR values of efficiency and cost savings may resonate with economic agencies, whereas equity and social justice may be more important for social welfare agencies. Because roles and influences vary between countries, HPSR researchers must understand the specifics of their country's processes of priority setting, strategy and budgeting.

Global shifts towards interdisciplinary research, including HPSR, recognise that complex problems often require holistic solutions. HPSR, as a large, interdisciplinary umbrella, offers a unique ability to convene researchers from other disciplines and bridge sectors. Engaging related disciplines as partners could increase trust and mutual capabilities and might increase the visibility of HPSR, as well as providing a valuable opportunity to address wider social determinants of health.

The COVID-19 pandemic has led to significant new funding for vaccines, diagnostics and treatments ${ }^{23}$ but funding for HPSR remains relatively low. Gilson et al. outline how HPSR can address short-term crises while also building stronger, more resilient people-centred systems for the future. ${ }^{24}$ Now is the time to advocate to include HPSR in the post-pandemic recovery process. This will require global collaboration.

Partnering with multilateral organisations, bilateral organisations, the private sector, and the health systems community is essential and important for developing common understandings of HPSR. One strategy is to develop unified search terms. When conducting a bibliometric analysis, we noted the lack of unified search terms or MeSH terms (Medical Subject Headings) relevant to HPSR. Although rigorous and comprehensive bibliometric analyses have been carried out in the field, search terms vary between them ${ }^{5,21,25}$, pointing to the need for common HPSR- specific MeSH terms. 


\section{Limitations}

The most significant limitation to this study is data availability; this is summarised in the methodology section. This was mitigated by providing descriptive statistics and triangulating with qualitative data where possible. Additionally, qualitative interviews may have introduced bias because the underlying values and interests of the interviewees potentially influenced their perceptions and responses. Notwithstanding these limitations, this study brings together collective knowledge across LMICs and has the potential to contribute to wider HPSR funding recommendations.

\section{Recommendations}

These recommendations speak to HPSR stakeholders and aim to overcome current challenges related to domestic HPSR funding.

\section{Box 1. Recommendations}

1. HPSR funding at the national level is almost invisible. Mechanisms to address this include:

- Committing funds to HPSR within national or institutional budgets, such as by creating a separate budget line

- Creating a global database for HPSR funding.

2. Advocating for the promise of HPSR to relevant stakeholders, framing HPSR in a way that is attractive to them

3. Global collaboration can help:

- Advocate for a common understanding of HPSR

- Advocate for HPSR-specific MeSH terms.

4. Incorporating HPSR into the post-COVID-19 pandemic recovery process to help create stronger health systems

\section{Conclusion}

Despite the importance of HPSR for implementation and evaluation of health policies, there remain significant challenges with domestic funding for this type of research. We explored several key themes that explained why domestic HPSR funding remains invisible.

Our findings inform the development of concrete and realistic strategies for key stakeholders in the HPSR space in LMICs. Rigorous advocacy efforts and political action will be required to convince national research funders and ministries of health and finance to invest in HPSR for stronger health systems.

\section{Acknowledgements}

We would like to acknowledge the Regional Principal Investigators who led the work in their respective region (in alphabetical order): Dr Francisco BecerraPosada, Dr George Gotsadze, Dr Swee Kheng Khor, Dr Manu Mathur, Dr Maha El Rabbat, Dr K Srinath Reddy and Dr Jesse Uneke; their teams and all stakeholders who participated in the interviews.

Special thanks to Dr K Srinath Reddy and Dr Swee Kheng Khor for their leadership and for developing the global report, and to Dr Abdul Ghaffar, Dr Marta Feletto, Dr Zubin Shroff and Dr Kabir Sheikh for their valuable feedback and guidance.

This work was supported by the Alliance for Health Policy and Systems Research, World Health Organization. The authors are themselves alone responsible for the views expressed in the article. This article does not represent the views, decisions or policies of the Alliance for Health Policy and Systems Research.

\section{Peer review and provenance}

Externally peer reviewed, commissioned.

\section{Competing interests}

None declared.

\section{Author contributions}

GL was responsible for drafting, design, data collection, analysis and editing of the manuscript. LZ, SH and SY were responsibel for data collection, analysis and drafting of the manuscript. All authors contributed to and approved the final manuscript.

\section{References}

1. World Health Organization. What is health policy and systems research (HPSR)? Geneva: WHO; 2014 [cited 2015 Feb]. Available from: ahpsr.who.int/what-we-do/ what-is-health-policy-and-systems-research-(hpsr)

2. Gilson L. Alliance for Health Policy and Systems Research, World Health Organization. Health policy and systems research: a methodology reader. Geneva: WHO; 2012 [cited 2021 Sep 29]. Available from: www.who.int/ alliance-hpsr/resources/alliancehpsr_reader.pdf?ua=1

3. World Health Organization, Alliance for Health Policy and Systems Research. World report on health policy and systems research: HPSR. Geneva: WHO; 2017 [cited 2021 Jun 2]. Available from: apps.who.int/iris/bitstream/ handle/10665/255051/9789241512268-eng.pdf;jsessionid $=01 \mathrm{~B} 1 \mathrm{~A} 31 \mathrm{~B} 5 \mathrm{~B} 6563420175 \mathrm{A00D5004446 \textrm {D }}$ ? sequence $=1$ 
4. World Health Organization. Everybody's business Strengthening health systems to improve health outcomes: WHO's framework for action. Geneva: WHO; 2007 [cited 2021 Sep 29]. Available from: www.who.int/ healthsystems/strategy/everybodys_business.pdf

5. Grépin KA, Pinkstaff CB, Shroff ZC, Ghaffar A. Donor funding health policy and systems research in low- and middle-income countries: how much, from where and to whom. Health Res Policy Syst. 2017;15(1):68.

6. Hafner T, Shiffman J. The emergence of global attention to health systems strengthening. Health Policy Plan. 2013;28(1):41-50.

7. Ministerial Summit on Health Research. Report by the Secretariat, WHA 58/22. Geneva: WHO; 2005 [cited 2021 Sep 29]. Available from: apps.who.int/gb/ebwha/ pdf_files/WHA58/A58_22-en.pdf

8. Bennett S, Adam T, Zarowsky C, Tangcharoensathien V, Ranson K, Evans T, et al. From Mexico to Mali: progress in health policy and systems research. Lancet. 2008;372(9649):1571-8.

9. Gonzalez Block MA, Mills A. Assessing capacity for health policy and systems research in low and middle income countries*. Health Res Policy Syst. 2003 Dec;1(1):1.

10. Yamey G, Ogbuoji O, Nonvignon J. Middle-income countries graduating from health aid: transforming daunting challenges into smooth transitions. PLOS Med. 2019;16(6):e1002837.

11. Bennett S, Frenk J, Mills A. The evolution of the field of Health Policy and Systems Research and outstanding challenges. Health Res Policy Syst. 2018 Dec;16(1):43

12. Lin V, Ghaffar A, Khor SK, Reddy KS. Strengthening health systems globally: a lingering challenge of funding. Public Health Res Pract. 2021;31(4):e3142115.

13. Gotsadze G. Political determinants and attitudes to HPSR funding in the countries of the former Soviet Union. Report prepared for the WHO Alliance of Health Policy and Systems Research; November 2020. Available from authors.

14. Becerra-Posada F, dos Santos Boeira L, GarcíaGodoy MB, Lloyd E, Martínez-Sánchez HX, O'Donnell C, et al. Politics and political determinants of health policy and systems research funding in selected countries in Latin America and the Caribbean. Report prepared for the WHO Alliance of Health Policy and Systems Research; 2020 Nov. Available from authors.
15. El Rabbat M, Mekky R. Political determinants and attitudes to HPSR funding in the Eastern Mediterranean Region. MENA Health Policy Forum, report prepared for the WHO Alliance of Health Policy and Systems Research; 2020 Nov. Available from authors.

16. Khor SK. Determinants of HPSR funding in selected countries in the Western Pacific region. The Western Pacific regional report prepared for the Alliance for Health Policy and Systems Research; 2020 Nov. Available from authors.

17. Reddy KS, Mathur MR, Selvaraj S, Kumar P, Gurung A. Political determinants and landscape of HPSR funding in WHO South East Asia region. Report prepared for the WHO Alliance of Health Policy and Systems Research; 2020 Nov. Available from authors.

18. Uneke J. Survey on political determinants and attitudes to HPSR funding in selected African countries. Report prepared for the WHO Alliance for Health Policy and Systems Research; 2020 Nov. Available from authors.

19. Devex. Development Funding. Washington DC: Devex; 2021 [cited 2021 Oct 1]. Available from: www.devex.com/ funding-overview

20. Khor SK. Political determinants of HPSR funding. The Global Report prepared for the Alliance of Health Policy and Systems Research; 2020 Dec. Available from authors.

21. Adam T, Ahmad S, Bigdeli M, Ghaffar A, Røttingen J-A. Trends in health policy and systems research over the past decade: still too little capacity in low-income countries. PLoS ONE. 2011 Nov 22;6(11):e27263.

22. Koon AD, Hawkins B, Mayhew SH. Framing and the health policy process: a scoping review. Health Policy Plan. 2016;31(6):801-16.

23. World Health Organization. G7 leaders commit US\$ 4.3 billion to finance global equitable access to tests, treatments and vaccines in 2021. Geneva: WHO; 2021 [cited 2021 Sep 15]. Available from: www.who.int/news/ item/19-02-2021-g7-leaders-commit-us-4.3-billion-tofinance-global-equitable-access-to-tests-treatments-andvaccines-in-2021

24. Gilson L, Marchal B, Ayepong I, Barasa E, Dossou J-P, George A, et al. What role can health policy and systems research play in supporting responses to COVID-19 that strengthen socially just health systems? Health Policy Plan. 2020;35(9):1231-6.

25. English KM, Pourbohloul B. Increasing health policy and systems research capacity in low- and middleincome countries: results from a bibliometric analysis. Health Res Policy Syst. 2017 Dec;15(1):64.

\section{Copyright: (c) (C)}

(C) 2021 Lamba et al. This article is licensed under a Creative Commons Attribution 3.0 IGO Licence, which allows others to redistribute, adapt and share this work for any purpose provided they attribute the work and indicate if changes were made. See: https://creativecommons.org/ licenses/by/3.0/igo/ 